\title{
Drinking pattern and blood pressure among non-hypertensive current drinkers: findings from 1999-2004 National Health and Nutrition Examination Survey
}

This article was published in the following Dove Press journal:

Clinical Epidemiology

25 January 2013

Number of times this article has been viewed

\author{
Amy Z Fan' \\ Yan $\mathrm{Li}^{2}$ \\ Laurie D Elam-Evans' \\ Lina Balluz' \\ 'Division of Behavioral Surveillance, \\ Public Health Surveillance and \\ Informatics Program Office (PHSIPO), \\ Office of Surveillance, Epidemiology \\ and Laboratory Services (OSELS), \\ Centers for Disease Control and \\ Prevention, Atlanta, GA, USA; \\ ${ }^{2}$ Division of Public Health, Georgia \\ Department of Community Health, \\ Atlanta, GA, USA
}

\begin{abstract}
Context and objective: Epidemiological studies show the apparent link between excessive alcohol consumption and hypertension. However, the association between alcohol intake and blood pressure among non-hypertensive individuals is scarcely examined.

Methods: This analysis included participants in the 1999-2004 National Health and Nutrition Examination Survey who were aged 20 to 84 years without a diagnosis of cardiovascular disease, hypertension or pregnancy, whose systolic/diastolic blood pressure (SBP/DBP) was lower than 140/90 $\mathrm{mmHg}$, who were not on antihypertensive medication, and who consumed 12 drinks or more during the past 12 months $(\mathrm{N}=3957)$. Average drinking volume (average alcohol intake per day), usual drinking quantity (drinks per day when drinking) and frequency of binge drinking were used to predict SBP/DBP. Covariates included age, gender, race/ethnicity, education level, smoking status, average physical activity level, and daily hours spent on TV/ video/computer.
\end{abstract}

Results: Drinking volume was directly associated with higher SBP in a linear dependent manner (an increment of $10 \mathrm{~g}$ of alcohol per day increased average SBP by $1 \mathrm{mmHg}$ among both men and women). Drinking above the US Dietary Guidelines (men more than two drinks and women more than one drink per drinking day) was associated with higher SBP. Binge drinking was associated with both higher SBP and higher DBP. Average intake greater than two drinks per day was particularly associated with higher DBP among women $(P=0.0003)$.

Conclusion: This analysis from a population-based survey indicates a direct association between higher alcohol consumption and a higher prevalence of prehypertension among nonhypertensive drinkers.

Keywords: blood pressure, drinking, ethanol, life style, prehypertension

\section{Introduction}

It is well established that excessive alcohol consumption is associated with elevated blood pressure. However, low to moderate levels of drinking are common among drinkers who have not yet developed hypertension. Whether or not low to moderate levels of drinking are associated with elevated blood pressure is controversial. Some population cohort ${ }^{1-4}$ and cross-sectional studies ${ }^{5-8}$ reported a positive association between levels of alcohol consumption and blood pressure, even from the lowest levels of consumption. ${ }^{9-12}$ Other studies revealed a J-shaped or U-shaped alcoholblood pressure association. ${ }^{13-15}$ Gender-differential associations were also reported. ${ }^{16}$ However, the controversial results in the association of blood pressure with low levels of consumption may be related to methodological approaches. For example, in almost 
all such studies, non-drinkers were used as the reference group. This may not be appropriate because non-drinkers are a heterogeneous group consisting of former drinkers, lifelong abstainers and irregular abstainers who may have preexisting health problems. Furthermore, whether drinking patterns play a role in hypertensive risk has not been investigated in depth.

The present study aimed to examine the association of drinking patterns with blood pressure among non-hypertensive current drinkers. By restricting study populations to non-hypertensive drinkers, we attempted to establish the association of low to moderate levels of alcohol consumption with blood pressure. We also aimed to examine whether the associations are different between men and women.

\section{Materials and methods Data source}

Data were obtained from the 1999-2004 National Health and Nutrition Examination Survey (NHANES), a population-based survey of the non-institutionalized US population. NHANES includes both an interview and a physical examination. We restricted our analysis to current drinkers (participants who consumed 12 or more alcoholic drinks during the past 12 months) aged 20 to 84 years, and who fasted at least 8 hours before the blood draw. We excluded those who had been diagnosed as having high blood pressure; whose actual measurements of blood pressure exceeded 140/90 mmHg; who were on antihypertensive medication; who had had a diagnosis of cardiovascular disease (angina/heart attack/ coronary heart disease, heart failure, stroke), who were pregnant; who had reduced their consumption of alcohol following a doctor's advice. This last exclusion was made to ensure that drinking habits had not changed because of health conditions relevant to the study outcome. This yielded 3957 participants with complete data for both blood pressure and alcohol consumption. Full details of the NHANES 1999-2004 design are available online. ${ }^{17}$

\section{Measures}

\section{Alcohol consumption patterns}

Measures of current drinking patterns included frequency, usual quantity, drinking exceeding the US Dietary Guidelines, and frequency of binge drinking. Frequency was assessed by asking "In the past 12 months, how often did you drink any alcoholic beverages?" We grouped responses into 3 categories ( $<1$ day per week, $1-2$ days per week, $\geq 3$ days per week). Usual quantity was assessed by the question "On those days when you drank alcoholic beverages, on the average, how many drinks did you have?" We grouped responses into 3 categories (1,2, and $\geq 3$ drinks per day when drinking). Men who consumed $>2$ drinks/day (ie, who usually drank 3 or more per day when drinking) and women who consumed $>1$ drink/day (ie, who usually drank 2 or more per day when drinking) were classified as drinking in excess of the US Dietary Guidelines ${ }^{18}$ and were defined as drinking exceeding the Guideline. Frequency of binge drinking was assessed by asking about the "number of days you had five or more drinks in the past 12 months." We grouped responses into 3 categories (no binge drinking, $<$ once per week, and $\geq$ once per week). Those who reported binge drinking $\geq$ once per week were defined as frequent binge drinkers. ${ }^{19}$

\section{Measurement of blood pressure} and definition of prehypertension

Average SBP and DBP were obtained according to the analytic protocol http://www.cdc.gov/nchs/nhanes/nhanes20012002/BPX_B.htm. Briefly, if only one blood pressure reading was obtained, that reading was the average. If there was more than one blood pressure reading, the first reading was always excluded from the average. If only two blood pressure readings were obtained, the second blood pressure reading was the average. Prehypertension is defined as an average systolic pressure of 120 to $139 \mathrm{mmHg}$ or an average diastolic pressure of 80 to $89 \mathrm{mmHg}$.

\section{Covariates and potential confounders}

Demographic variables (age, gender, race/ethnicity, years of education), family medical history (heart attack, stroke, diabetes, hypertension), dietary practice (gender-specific quartiles of saturated fat intake and of dietary fiber intake), video-based physical inactivity (daily hours of TV, video, or computer use outside of work), habitual daily activity level (sedentary, light, some moderate-to-vigorous activity), and tobacco use (never, former, and current smoker) were considered as covariates in the regression models. We included both habitual physical activity level and hours per day spent on computer, video or TV because they represent different dimensions of physical activity and both were significant in the regression model.

\section{Statistical analysis}

The analysis was performed using SAS-callable SUDAAN 10.0 (Research Triangle Institute, Research Triangle 
Park, NC) to account for the complex sampling design of the NHANES. Average systolic and diastolic blood pressures were used as dependent variables in multiple regression models. Separate analyses were carried out by gender. Least-square means (which can be interpreted as adjusted means) of blood pressures were obtained by drinking volume category. Model 1 was adjusted for age and race/ethnicity only. Model 2 was adjusted for age, race/ethnicity, education attainment, BMI category, smoking status, usual physical activity level, and hours per day spent on computer, video or TV. We then tested the association of blood pressures with different drinking pattern variables including: drinks per day when drinking; drinking exceeding the US Dietary Guidelines; drinking frequency; and frequency of binge drinking. A linear trend test was carried out to detect whether blood pressure measures varied across different categories of the drinking pattern measures. Finally, we used log linear regression analyses to obtain multivariate-adjusted prevalence ratios (PRs) for prehypertension by drinking pattern variables. $P$-values were 2 -sided, with $P<0.05$ considered significant.

\section{Results}

A total of 3957 eligible current drinkers were included in the analysis from NHANES 1999-2004. Overall, male drinkers $(\mathrm{n}=2456)$ had a higher average systolic blood pressure (117.7 versus $111.8 \mathrm{mmHg}$ ) and diastolic blood pressure (71.7 versus $69.4 \mathrm{mmHg}$ ) than female drinkers $(\mathrm{n}=1501)$. A large proportion of the non-hypertensive current drinkers had prehypertension [52\% (95\% CI: $49 \%-55 \%$ ) among males and 29\% (95\% CI: $26 \%-32 \%$ ) among females]. Male current drinkers consumed more drinks in terms of volume, quantity and frequency than female drinkers. Male drinkers also had more episodes of binge drinking than female drinkers. However, more female drinkers exceeded the US Dietary Guidelines (greater than one drink per day when drinking) compared to male drinkers (greater than two drinks per day when drinking) (Table 1).

Drinking volume was associated with higher SBP in a linear dependent manner (an increment of $10 \mathrm{~g}$ of alcohol per day was associated with an increase of SBP by $1 \mathrm{mmHg}$ on average) among both men and women (Table 2). There was a differential volume-BP association between men and women. DBP increased linearly with drinking volume among women, while there was no
Table I Characteristics of eligible current drinkers by gender $(\mathrm{n}=3957)$

\begin{tabular}{|c|c|c|c|}
\hline Characteristic & $\begin{array}{l}\text { Men } \\
(n=2456)\end{array}$ & $\begin{array}{l}\text { Women } \\
(n=\mid 50 I)\end{array}$ & $\begin{array}{l}P \text { for } \\
\text { difference* }\end{array}$ \\
\hline \multicolumn{4}{|c|}{ Continuous variables, mean (SE) } \\
\hline Age in years & $38.4(0.4)$ & $38.9(0.3)$ & 0.33 \\
\hline $\begin{array}{l}\text { Systolic blood pressure } \\
(\mathrm{mmHg})\end{array}$ & $117.7(0.4)$ & $111.8(0.4)$ & $<0.001$ \\
\hline $\begin{array}{l}\text { Diastolic blood pressure } \\
(\mathrm{mmHg})\end{array}$ & $71.7(0.2)$ & $69.4(0.3)$ & $<0.001$ \\
\hline \multicolumn{4}{|c|}{ Categorical variables, \% (SE) } \\
\hline Prehypertension (\%) & $51.9(1.5)$ & $28.8(1.5)$ & $<0.001$ \\
\hline Race/ethnicity & & & $<0.001$ \\
\hline Non-Hispanic white & $73.0(1.7)$ & $79.1(1.8)$ & \\
\hline Non-Hispanic black & $7.7(0.7)$ & $7.2(0.7)$ & \\
\hline Mexican American & $10.2(1.0)$ & $5.1(0.7)$ & \\
\hline Other & $9.2(1.5)$ & $8.6(1.4)$ & \\
\hline \multicolumn{4}{|l|}{ Education } \\
\hline $\begin{array}{l}\text { Lower than high school } \\
\text { graduate }\end{array}$ & $17.2(1.0)$ & $10.5(0.9)$ & \\
\hline High school graduate & $25.0(1.2)$ & $22.6(1.4)$ & \\
\hline More than high school & $57.9(1.5)$ & $66.9(1.7)$ & \\
\hline \multicolumn{3}{|c|}{ Volume (drinks during the past 30 days) } & $<0.001$ \\
\hline $1-9$ & $40.7(1.0)$ & $62.3(1.6)$ & \\
\hline $10-29$ & $26.3(1.0)$ & $22.6(1.4)$ & \\
\hline $30-59$ & $16.0(0.7)$ & $9.8(0.9)$ & \\
\hline$\geq 60$ & $17.0(0.7)$ & $5.3(0.7)$ & \\
\hline \multicolumn{3}{|c|}{ Quantity (drinks per day when drinking) } & $<0.001$ \\
\hline 1 & $17.5(1.2)$ & $28.4(1.6)$ & \\
\hline 2 & $27.9(1.2)$ & $36.7(1.5)$ & \\
\hline$\geq 3$ & $54.6(1.7)$ & $34.8(1.7)$ & \\
\hline \multicolumn{3}{|c|}{ Drinking exceeding the US Dietary Guidelines } & $<0.001$ \\
\hline No & $45.4(1.7)$ & $28.4(1.6)$ & \\
\hline Yes & $54.6(1.7)$ & $71.6(1.6)$ & \\
\hline \multicolumn{3}{|c|}{ Frequency (drinking days per week) } & $<0.001$ \\
\hline$<1$ & $34.4(1.1)$ & $49.4(1.7)$ & \\
\hline $\mathrm{I}-2$ & $36.6(1.4)$ & $31.5(1.3)$ & \\
\hline$\geq 3$ & $29.1(1.3)$ & I9.I (I.4) & \\
\hline \multicolumn{3}{|c|}{ Frequency of binge drinking (times per week) } & $<0.001$ \\
\hline 0 & $34.8(1.3)$ & $61.5(1.5)$ & \\
\hline$<1$ & $45.9(1.4)$ & $32.9(1.7)$ & \\
\hline$\geq 1$ & $19.3(1.0)$ & $5.6(0.7)$ & \\
\hline
\end{tabular}

Note: NHANES, 1999-2004. $* P$ for difference was obtained from $t$-tests for continuous variables and Chi-square tests for categorical variables.

Abbreviations: NHANES, National Health and Nutrition Examination Survey; $\mathrm{SE}$, standard error.

statistical difference of DBP at different levels of drinking volume among men.

Both SBP $(P$ for linear trend $=0.001)$ and DBP $(P$ for linear trend $=0.03$ ) increased with increasing alcohol quantity among male drinkers (Table 3 ). Drinking exceeding the Guidelines was associated with higher SBP among male drinkers $(P=0.002)$. These associations were not significant among females. 
Table 2 Adjusted means (SEs) of systolic and diastolic blood pressure by gender and drinking volume category

\begin{tabular}{|c|c|c|c|c|c|}
\hline & \multicolumn{4}{|c|}{ Drinks during the past 30 days } & \multirow[t]{2}{*}{$P$ for linear trend } \\
\hline & I-9 & $10-29$ & $30-59$ & $\geq 60$ & \\
\hline Women, $n$ & 962 & 329 & 133 & 77 & \\
\hline \multicolumn{6}{|l|}{ SBP, mmHg } \\
\hline Model I* & II $4.6(0.6)$ & II6.I (0.8) & II8.I (I.7) & $119.9(1.2)$ & $<0.001$ \\
\hline Model $2^{\dagger}$ & $115.0(0.8)$ & $117.4(1.3)$ & $120.9(3.0)$ & $124.8(2.1)$ & 0.0018 \\
\hline \multicolumn{6}{|l|}{$\mathrm{DBP}, \mathrm{mmHg}$} \\
\hline Model I & $70.6(0.3)$ & $70.8(0.5)$ & $71.3(1.2)$ & $72.9(0.9)$ & 0.0083 \\
\hline Model 2 & $71.3(0.5)$ & $71.0(0.7)$ & $74.3(2.5)$ & $77.1(1.0)$ & $<0.001$ \\
\hline Men, $\mathbf{n}$ & 1039 & 643 & 377 & 397 & \\
\hline \multicolumn{6}{|l|}{$\mathrm{SBP}, \mathrm{mmHg}$} \\
\hline Model I & I $20.0(0.6)$ & I $20.7(0.6)$ & I22.I (0.8) & $123.4(0.9)$ & $<0.001$ \\
\hline Model 2 & $118.9(1.0)$ & $120.2(1.1)$ & $121.9(1.5)$ & $\mid 23.1(0.5)$ & $<0.001$ \\
\hline \multicolumn{6}{|l|}{$\mathrm{DBP}, \mathrm{mmHg}$} \\
\hline Model I & $73.3(0.3)$ & $73.5(0.5)$ & $74.1(0.6)$ & $74.1(0.6)$ & 0.19 \\
\hline Model 2 & $73.2(0.6)$ & $72.6(0.7)$ & $74.1(1.0)$ & $74.6(0.8)$ & 0.056 \\
\hline
\end{tabular}

Notes: NHANES, 1999-2004. *Model I was adjusted for age and race/ethnicity; ${ }^{\dagger}$ model 2 was adjusted for age, race/ethnicity, education attainment, BMI category, smoking status, usual physical activity level, and hours per day spent on computer, video or TV.

Abbreviations: NHANES, National Health and Nutrition Examination Survey; SE, standard error; SBP, systolic blood pressure; DBP, diastolic blood pressure.

Female drinkers who drank more frequently (more days per week $)$ manifested higher SBP $(P$ for linear trend $=0.009)$ and DBP $(P$ for linear trend $=0.04)$ (Table 4$)$. Male drinkers who drank more frequently manifested higher SBP ( $P$ for linear trend $=0.03$ ). Higher frequency of binge drinking was associated with elevated SBP among men ( $P$ for linear trend $=0.005$ ).

The association of drinking patterns with prehypertension by gender is shown in Table 5. Consuming more than 60 drinks during the past 30 days and drinking three days or more frequently per week was significantly associated with higher prevalence of prehypertension for male and female drinkers. Consuming 3 drinks or more per day when drinking, or drinking exceeding the Guidelines, or having one or more binge drinking episode per week was associated with higher prevalence of prehypertension only among male drinkers.

\section{Discussion}

This population-based study revealed a significant association between drinking patterns and blood pressure among non-hypertensive current drinkers. Total drinking volume is associated with SBP in a linear manner in both men and women, which indicates that alcohol consumption may be associated with prehypertension risk.

The alcohol-blood pressure associations appear to be different by gender. Higher drinking quantity and frequency of binge drinking were associated with higher blood pressure in men but not in women. This differential association may be related to the fact that male drinkers usually drank more frequently with a higher quantity and had more binge drinking episodes. Therefore, the adverse effects become more manifest in male drinkers. This can explain why a higher proportion of diagnosed high

Table 3 Adjusted means (SEs) of systolic and diastolic blood pressures by gender and drinking quantity category*

\begin{tabular}{|c|c|c|c|c|c|c|c|}
\hline & \multicolumn{3}{|c|}{ Drinks per day when drinking } & \multirow{3}{*}{$\begin{array}{l}P \text { for linear } \\
\text { trend }\end{array}$} & \multirow{2}{*}{\multicolumn{2}{|c|}{$\begin{array}{l}\text { Drinking exceeding the } \\
\text { US Dietary Guidelines }\end{array}$}} & \multirow{3}{*}{$\begin{array}{l}P \text { for } \\
\text { difference }\end{array}$} \\
\hline & \multirow[t]{2}{*}{1} & \multirow[t]{2}{*}{2} & \multirow[t]{2}{*}{$\geq 3$} & & & & \\
\hline & & & & & No & Yes & \\
\hline Women, $\mathrm{n}$ & 433 & 522 & 546 & & 433 & 1068 & \\
\hline $\mathrm{SBP}, \mathrm{mmHg}$ & I I $3.8(1.4)$ & 119.1 (1.9) & $116.3(1.4)$ & 0.09 & $111.3(1.1)$ & $112.9(1.0)$ & 0.19 \\
\hline $\mathrm{DBP}, \mathrm{mmHg}$ & $70.6(0.7)$ & $73.3(1.2)$ & $71.2(0.8)$ & 0.09 & $69.4(0.6)$ & $70.1(0.7)$ & 0.50 \\
\hline Men, $\mathbf{n}$ & 438 & 635 & 1383 & & 1073 & 1383 & \\
\hline $\mathrm{SBP}, \mathrm{mmHg}$ & $118.6(1.5)$ & $118.9(0.9)$ & $122.1(0.6)$ & $<0.001$ & II $15.8(0.7)$ & II $8.7(0.5)$ & 0.0017 \\
\hline $\mathrm{DBP}, \mathrm{mmHg}$ & $72.1(0.9)$ & $74.1(0.8)$ & $73.6(0.5)$ & 0.028 & $72.1(0.7)$ & $70.7(0.6)$ & 0.12 \\
\hline
\end{tabular}

Notes: NHANES, 1999-2004. *The estimates were obtained after adjustment for age, race/ethnicity, educational attainment, BMI category, smoking status, usual physical activity level, and daily hours spent on computer, video or TV.

Abbreviations: NHANES, National Health and Nutrition Examination Survey; SE, standard error; SBP, systolic blood pressure; DBP, diastolic blood pressure. 
Table 4 Adjusted means (SEs) of systolic and diastolic blood pressures by gender and drinking frequency category*

\begin{tabular}{|c|c|c|c|c|c|c|c|c|}
\hline & \multicolumn{3}{|l|}{ Frequency } & \multirow{2}{*}{$\begin{array}{l}P \text { for linear } \\
\text { trend }\end{array}$} & \multicolumn{3}{|c|}{ Frequency of binge drinking } & \multirow{2}{*}{$\begin{array}{l}P \text { for linear } \\
\text { trend }\end{array}$} \\
\hline & $<$ I day/week & I-2 days/week & $\geq 3$ days/week & & None & $<$ once/week & $\geq$ once/week & \\
\hline Women, $\mathrm{n}$ & 784 & 457 & 260 & & 938 & 471 & 89 & \\
\hline SBP, mmHg & II $5.5(0.8)$ & $115.7(1.4)$ & $120.7(1.9)$ & 0.0089 & $116.2(1.2)$ & $117.6(1.1)$ & $117.8(2.1)$ & 0.51 \\
\hline $\mathrm{DBP}, \mathrm{mmHg}$ & $71.6(0.6)$ & $70.6(0.6)$ & $74.2(1.5)$ & 0.04 & $71.5(0.8)$ & $72.6(0.9)$ & $70.5(2.6)$ & 0.68 \\
\hline Men, $\mathbf{n}$ & 908 & 889 & 659 & & 901 & 1060 & 491 & \\
\hline SBP, mmHg & II9.I (0.9) & I $20.4(0.8)$ & $122.2(1.0)$ & 0.026 & $119.1(1.1)$ & I $20.4(\mid .0)$ & I23.I (0.8) & 0.0053 \\
\hline $\mathrm{DBP}, \mathrm{mmHg}$ & $73.2(0.6)$ & $73.4(0.6)$ & $73.8(0.9)$ & 0.54 & $73.2(0.9)$ & $72.8(0.7)$ & $75.2(0.8)$ & 0.16 \\
\hline
\end{tabular}

Notes: NHANES, 1999-2004. *The estimates were obtained after adjustment for age, race/ethnicity, education attainment, BMI category, smoking status, usual physical activity level, and hours per day spent on computer, video or TV.

Abbreviations: NHANES, National Health and Nutrition Examination Survey; SE, standard error; SBP, systolic blood pressure; DBP, diastolic blood pressure.

blood pressure in men is attributable to alcohol consumption than in women..$^{20}$

In previous studies, when non-drinkers were used as the reference group ${ }^{16}$ a J-shaped alcohol-hypertension association among women and a linear association among men was frequently reported. However, our results do not support the notion that "light-to-moderate alcohol consumption decreased hypertension risk in women and increased risk in men" ${ }^{16}$ The use of non-drinkers as the referent groups has been problematic. When examining alcohol-blood pressure association

Table 5 Multivariate-adjusted* prevalence ratios for prehypertension in association with drinking patterns ${ }^{\dagger}$

\begin{tabular}{|c|c|c|}
\hline & $\begin{array}{l}\text { Men } \\
\text { PR }(95 \% \mathrm{Cl})\end{array}$ & $\begin{array}{l}\text { Women } \\
\text { PR }(95 \% \mathrm{Cl})\end{array}$ \\
\hline \multicolumn{3}{|c|}{ Volume (drinks during the past 30 days) } \\
\hline $1-9$ & 1.00 & 1.00 \\
\hline $10-29$ & $1.21(1.06-1.39)$ & $1.12(0.87-1.46)$ \\
\hline $30-59$ & $1.23(1.00-1.5 I)$ & $1.22(0.86-1.71)$ \\
\hline$\geq 60$ & $1.34(1.16-1.55)$ & $1.78(1.44-2.19)$ \\
\hline \multicolumn{3}{|c|}{ Quantity (drinks per drinking day) } \\
\hline I & 1.00 & 1.00 \\
\hline 2 & $1.20(1.00-1.44)$ & $1.15(0.78-1.69)$ \\
\hline$\geq 3$ & $1.33(1.11-1.58)$ & I.0I (0.64-I.59) \\
\hline \multicolumn{3}{|c|}{ Drinking exceeding the US Dietary Guidelines } \\
\hline No & 1.00 & 1.00 \\
\hline Yes & $1.17(1.06-1.30)$ & I.II (0.77-I.59) \\
\hline \multicolumn{3}{|c|}{ Frequency (drinking days per week) } \\
\hline$<1$ & 1.00 & 1.00 \\
\hline $1-2$ & $1.18(1.03-1.35)$ & $0.97(0.76-1.24)$ \\
\hline$\geq 3$ & $1.26(1.09-1.45)$ & $1.33(1.04-1.69)$ \\
\hline \multicolumn{3}{|c|}{ Frequency of binge drinking (times per week) } \\
\hline 0 & 1.00 & 1.00 \\
\hline$<1$ & $1.05(0.87-1.26)$ & $1.00(0.69-1.45)$ \\
\hline$\geq 1$ & $1.26(1.08-1.53)$ & $\mathrm{I} .49(0.87-2.56)$ \\
\hline
\end{tabular}

Notes: NHANES, 1999-2004. *The estimates were prevalence ratios $(95 \% \mathrm{Cl})$ adjusted for age, race/ethnicity, educational attainment, BMI category, smoking status, usual physical activity level, and daily hours spent on computer, video or TV; tprehypertension is defined as systolic/diastolic blood pressure values of |20-139/ $80-89 \mathrm{mmHg}$.

Abbreviations: NHANES, National Health and Nutrition Examination Survey; $\mathrm{PR}$, prevalence ratio. among current drinkers, we observed that a threshold beyond which alcohol consumption begins to become harmful does not appear to exist.

Although only half of male current drinkers who were not hypertensive reported alcohol consumption that exceeded the Drinking Guidelines, about half of this population (52\%) already manifested prehypertension. Data from 2005-2006 NHANES estimated that 1 out of 4 persons aged 20 years or older in US has prehypertension. ${ }^{21}$ Some studies showed that alcohol consumption predicts prehypertension, ${ }^{22}$ and progression from prehypertension to hypertension. ${ }^{23-25}$ Randomized controlled trials show that reducing alcohol consumption lowers blood pressure in both non-hypertensive, and treated and untreated hypertensive subjects. ${ }^{26-28}$ Xin et al reported a $76 \%$ reduction in alcohol consumption was associated with decreasing blood pressure, and this relationship is dose-dependent. ${ }^{29}$ Questions remain as to whether the limit for sensible drinking (not to exceed two drinks on days when drinking) for males is really safe. The Seventh Report of the Joint National Committee on Prevention, Detection, Evaluation, and Treatment of High Blood Pressure actually recommended men of smaller body size to consume "no more than $0.5 \mathrm{oz}$ of ethanol (one drink) per day". ${ }^{30}$ In light of the risk of developing high blood pressure, it may be wise to advise all male drinkers to consume no more than one drink per day. However, it is still unclear whether an intervention to lower alcohol intake in moderate to heavy drinkers with above optimal to slightly elevated diastolic blood pressure could produce sustained reduction of blood pressure. ${ }^{31}$

In our study, drinking quantity, frequency of binge drinking, and drinking frequency were all related to the health outcome of our concern. In addition, risk and frequency of binge drinking increased with frequency of drinking. ${ }^{32}$ Therefore, researchers have recommended that drinking patterns should be taken into account in making drinking guidelines. For example, the National Institute on Alcohol 
Abuse and Alcoholism (NIAAA) Physicians' Guidelines incorporating both daily and weekly alcohol limits performed better in the prediction of a variety of alcohol-related outcomes than the US Dietary Guidelines. ${ }^{33}$

Our study revealed a dose dependent relationship between alcohol consumption and higher average blood pressure among non-hypertensives. In addition, the associations of drinking patterns with the prevalence of prehypertension were gender-related. Our findings added to the large body of evidence that alcohol consumption is harmful. Preventive counseling for alcohol use should be integrated in primary care. Limits for sensible drinking need to be revisited with more epidemiologic data using robust analytic methods. More intervention studies are needed to examine the extent of the reduction in alcohol intake to produce significant reduction in blood pressure levels among drinkers.

\section{Disclosure}

The findings and conclusions in this report are those of the authors and do not necessarily represent the official position of the Centers for Disease Control and Prevention. The authors report no conflicts of interest in this work.

\section{References}

1. Ascherio A, Rimm EB, Giovannucci EL, et al. A prospective study of nutritional factors and hypertension among US men. Circulation. 1992;86(5):1475-1484.

2. Colditz GA. A prospective assessment of moderate alcohol intake and major chronic diseases. Ann Epidemiol. 1990;1(2):167-177.

3. Stamler J, Caggiula AW, Grandits GA. Relation of body mass and alcohol, nutrient, fiber, and caffeine intakes to blood pressure in the special intervention and usual care groups in the Multiple Risk Factor Intervention Trial. Am J Clin Nutr. 1997;65(1 Suppl):338S-365S.

4. Witteman JC, Willett WC, Stampfer MJ, et al. Relation of moderate alcohol consumption and risk of systemic hypertension in women. $\mathrm{Am}$ J Cardiol. 1990;65(9):633-637.

5. Criqui MH, Wallace RB, Mishkel M, Barrett-Connor E, Heiss G. Alcohol consumption and blood pressure. The lipid research clinics prevalence study. Hypertension. 1981;3(5):557-565.

6. Klatsky AL, Friedman GD, Armstrong MA. The relationships between alcoholic beverage use and other traits to blood pressure: a new Kaiser Permanente study. Circulation. 1986;73(4):628-636.

7. Lang T, Degoulet P, Aime F, Devries C, Jacquinet-Salord MC, Fouriaud C. Relationship between alcohol consumption and hypertension prevalence and control in a French population. J Chronic Dis. 1987; 40(7):713-720.

8. Weissfeld JL, Johnson EH, Brock BM, Hawthorne VM. Sex and age interactions in the association between alcohol and blood pressure. Am J Epidemiol. 1988;128(3):559-569.

9. Cooke KM, Frost GW, Stokes GS. Blood pressure and its relationship to low levels of alcohol consumption. Clin Exp Pharmacol Physiol. 1983;10(3):229-233.

10. Dyer AR, Cutter GR, Liu KQ, et al. Alcohol intake and blood pressure in young adults: the CARDIA Study. J Clin Epidemiol. 1990;43(1):1-13.
11. Kimball AW, Friedman LA, Moore RD. Nonlinear modeling of alcohol consumption for analysis of beverage type effects and beverage preference effects. Am J Epidemiol. 1992;135(11):1287-1292.

12. Milon H, Froment A, Gaspard P, Guidollet J, Ripoll JP. Alcohol consumption and blood pressure in a French epidemiological study. Eur Heart J. 1982;3 Suppl C:59-64.

13. Jackson R, Stewart A, Beaglehole R, Scragg R. Alcohol consumption and blood pressure. Am J Epidemiol. 1985;122(6):1037-1044.

14. Rabbia F, Veglio F, Russo R, Schiavone D, Oliva S, Chiandussi L. Role of alcoholic beverages in essential hypertensive patients. Alcohol Alcohol. 1995;30(4):433-439.

15. Shaper AG, Wannamethee G, Whincup P. Alcohol and blood pressure in middle-aged British men. J Hum Hypertens. 1988;2(2): 71-78.

16. Sesso HD, Cook NR, Buring JE, Manson JE, Gaziano JM. Alcohol consumption and the risk of hypertension in women and men. Hypertension. 2008;51(4):1080-1087.

17. National Health and Nutrition Examination Survey. Available from: http://www.cdc.gov/nchs/nhanes.htm. Accessed July 6, 2011.

18. Dietary Guidelines for Americans, 2010. Available from: http://www. health.gov/dietaryguidelines/2010.asp. Accessed July 15, 2011.

19. Schulenberg J, O’Malley PM, Bachman JG, Wadsworth KN, Johnston LD. Getting drunk and growing up: trajectories of frequent binge drinking during the transition to young adulthood. J Stud Alcohol. 1996;57(3):289-304.

20. Campbell NR, Ashley MJ, Carruthers SG, Lacourciere Y, McKay DW. Lifestyle modifications to prevent and control hypertension. 3. Recommendations on alcohol consumption. Canadian Hypertension Society, Canadian Coalition for High Blood Pressure Prevention and Control, Laboratory Centre for Disease Control at Health Canada, Heart and Stroke Foundation of Canada. CMAJ. 1999;160(Suppl 9): S13-S20.

21. Lloyd-Jones D, Adams RJ, Brown TM, et al. Heart disease and stroke statistics - 2010 update: a report from the American Heart Association. Circulation. 2010;121(7):e46-e215.

22. Lee JH, Hwang SY, Kim EJ, Kim MJ. Comparison of risk factors between prehypertension and hypertension in Korean male industrial workers. Public Health Nurs. 2006;23(4):314-323.

23. Jorgensen RS, Maisto SA. Alcohol consumption and prehypertension: an investigation of university youth. Behav Med. 2008;34(1): 21-28.

24. Zheng L, Sun Z, Zhang X, et al. Predictors of progression from prehypertension to hypertension among rural Chinese adults: results from Liaoning Province. Eur J Cardiovasc Prev Rehabil. 2010;17(2): 217-222.

25. Tomiyama H, Matsumoto C, Yamada J, et al. Predictors of progression from prehypertension to hypertension in Japanese men. Am J Hypertens. 2009;22(6):630-636.

26. Puddey IB, Beilin LJ, Vandongen R, Rouse IL, Rogers P. Evidence for a direct effect of alcohol consumption on blood pressure in normotensive men. A randomized controlled trial. Hypertension. 1985;7(5):707-713.

27. Puddey IB, Beilin LJ, Vandongen R. Regular alcohol use raises blood pressure in treated hypertensive subjects. A randomised controlled trial. Lancet. 1987;1(8534):647-651.

28. Ueshima H, Mikawa K, Baba S, et al. Effect of reduced alcohol consumption on blood pressure in untreated hypertensive men. Hypertension. 1993;21(2):248-252.

29. Xin X, He J, Frontini MG, Ogden LG, Motsamai OI, Whelton PK. Effects of alcohol reduction on blood pressure: a meta-analysis of randomized controlled trials. Hypertension. 2001;38(5):1112-1117.

30. National High Blood Pressure Education Program. The Seventh Report of the Joint National Committee on Prevention, Detection, Evaluation, and Treatment of High Blood Pressure. Available from: http://www. nhlbi.nih.gov/guidelines/hypertension/jnc7full.pdf; 2004. 
31. Cushman WC, Cutler JA, Hanna E, et al. Prevention and Treatment of Hypertension Study (PATHS): effects of an alcohol treatment program on blood pressure. Arch Intern Med. 1998;158(11):1197-1207.

32. Paradis C, Demers A, Picard E, Graham K. The importance of drinking frequency in evaluating individuals' drinking patterns: implications for the development of national drinking guidelines. Addiction. 2009; 104(7):1179-1184.
33. Dawson DA. US low-risk drinking guidelines: an examination of four alternatives. Alcohol Clin Exp Res. 2000;24(12):1820-1829.

\section{Publish your work in this journal}

Clinical Epidemiology is an international, peer-reviewed, open access journal focusing on disease and drug epidemiology, identification of risk factors and screening procedures to develop optimal preventative initiatives and programs. Specific topics include: diagnosis, prognosis, treatment, screening, prevention, risk factor modification, systematic

Submit your manuscript here: http://www.dovepress.com/clinical-epidemiology-journal

\section{Dovepress}

reviews, risk \& safety of medical interventions, epidemiology \& biostatical methods, evaluation of guidelines, translational medicine, health policies \& economic evaluations. The manuscript management system is completely online and includes a very quick and fair peer-review system, which is all easy to use. 